\title{
Cracks Pattern Formation and Thermomechanical Fatigue in Die Steels
}

\author{
${ }^{1}$ Ilnar R. Mukhametzyanov, ${ }^{2}$ Mikhail S. Kolesnikov, ${ }^{3}$ Gulnara F. Mukhametzyanova, ${ }^{4}$ Vladimir I. Astaschenko \\ ${ }^{1-4}$ Kazan Federal University \\ Email: ilnarr116m@gmail.com; kolesnikov_kfu@mail.ru; gulnara-ineka@mail.ru; astvi-52@mail.ru
}

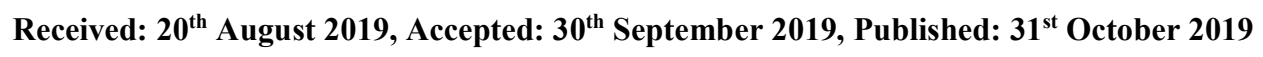

\begin{abstract}
Investigations are given of the influence of thermal, thermochemical treatment of die steels on the development of thermomechanical fatigue cracks depending on the temperature-force effects characteristic of hot deformation dies. As the evaluation criteria for the thermomechanical fatigue resistance of surface hardened die steels, the moment of nucleation, their quantity, and the depth of propagation were used. The study of the laws of the development of thermomechanical fatigue cracks in die steels in copper melts is carried out in an analogous manner, which provides a similarity to the operational loading of the material according to the local stress-strain state and the conditions of interaction with the molten melt. Dependences of the depth and number of cracks formed in 4X4VMFS DI22 die steel, hardened by various methods, on the number of loading cycles are established. It has been established that the performance of a stamping tool in a variant with diffusion hardening is determined by the specific laws of softening and destruction of contact zones. Moreover, the occurrence of cracks in the initial stages of operation is not decisive. The positive effect of boriding and nitriding on the performance of the dies is associated with increased structural stability of the diffusion saturation zones, which ensures the maintenance of a high level of mechanical characteristics of the tool working surfaces - hardness, strength, and as a result of high wear resistance. The analysis of the results of studies of the patterns of crack formation in steel 4X4VMFS DI22, subjected to various hardening methods, indicates the promising use of nitriding and boriding to increase the life of dies.
\end{abstract}

\section{Keywords}

Steel, Die, Fatigue, Crack, Hardening, Nitriding, Boriding.

\section{Introduction}

The high pace of development of engineering and other industries determine the ever-increasing need for highly resistant technological equipment for stamping and injection molding processes, which are experiencing a complex loading complex. Numerous factors affecting the durability of dies can be divided into metallurgical, technological, structural, operational. A variety of factors determines the complex nature of die wear - thermomechanical fatigue, crushing, wear, etc. The results of studies of tool materials using standard testing methods for special characteristics (resistance to crack development of thermomechanical fatigue, etc.) and mechanical properties do not provide sufficient information to predict the technological resistance equipment. This is due to the fact that the loading conditions of the samples do not correspond to the loading conditions of the equipment. In this regard, a systematic study of the laws of behavior of tool materials for dies of solid-liquid die stamping under specific conditions of temperature-force impact and interaction with melts characteristic of operational ones for a specific tool group is an urgent task [1 - 5].

Hardening of the working surfaces of a heavily loaded tool for hot deformation and injection molds using nitriding, cyanidation, etc. methods have received limited distribution. The latter is associated with low resistance to thermomechanical fatigue of diffusion saturation layers. The adverse effect of thermochemical treatment on the occurrence of thermomechanical fatigue cracks is explained by a high level of initial stresses in the layers due to microstructural heterogeneity, high hardness and, as a consequence, increased fragility [1, 2, 6 - 10].

In the present work, when studying the thermomechanical fatigue resistance of surface-hardened steel samples 4X4VMFS DI22 as applied to the loading of Avtoforge dies, a complex evaluation criterion is proposed that takes into account the number of cracks (n) and the average depth (Havg) due to the duration of the cyclic temperature force impact.

The purpose of the work is to establish the laws of formation of thermomechanical fatigue cracks in surface-hardened die steels in various ways to improve the performance of the die tool.

\section{Methods}

The study of the laws of development of thermomechanical fatigue cracks in die steels when interacting with a copper melt is carried out by the analog method according to the procedure [11], which provides a similarity to the operational loading of the material according to the local stress-strain state and the conditions of interaction with the molten melt. The schematic diagram of the testing of die steels is shown in Fig. 1. 


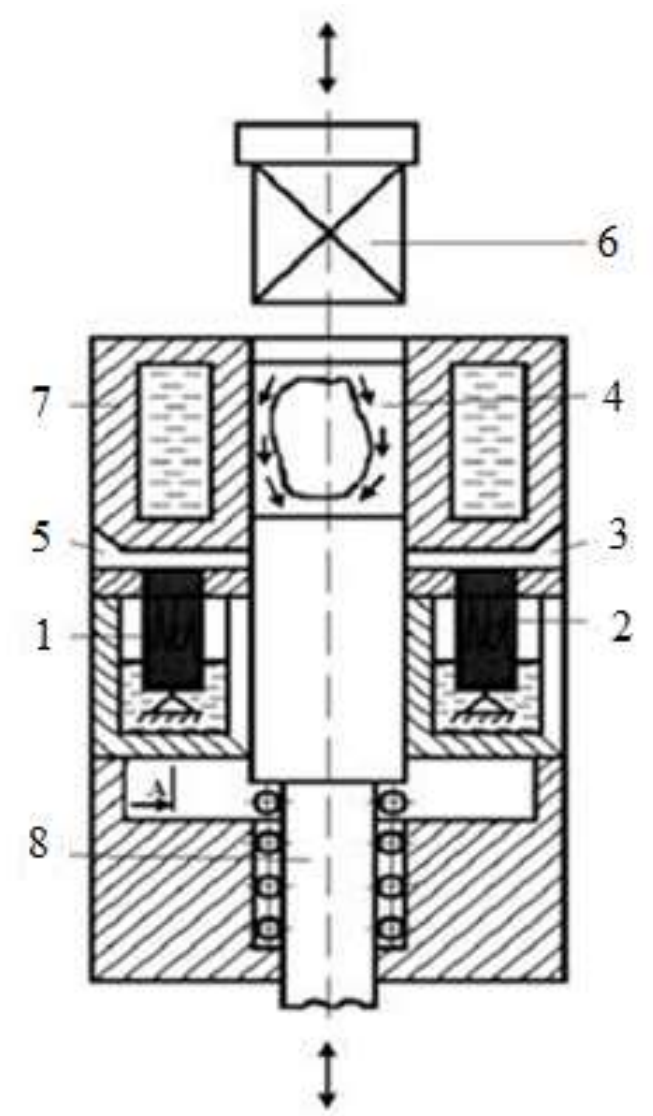

Fig. 1. Scheme of Testing Materials for Thermomechanical Fatigue

[1,2 - Samples; 3, 5 - Running Channels; 4 - Forged Bronze; 6 - Punch; 7 - Mold; 8 - Piston]

The tin-zinc-lead bronze melt was preliminarily cooled in a crystallizer to a two-phase solid-liquid state, then it was fed under pressure to the studied zone of die steel samples until complete crystallization. The studied samples 1,2 of rectangular cross section with dimensions of $2 \times 10 \times 80 \mathrm{~mm}$ were placed in a bath with a cooling medium. The upper zone of the samples through slotted running channels 3 and 5 was exposed to a movable solid-liquid tin-zinc-lead bronze alloy when it was pressed using a punch 6 from mold 7. During the pressing process, the partially crystallized bronze was destroyed and passing through the running channels 3 and 5, heated the studied zones of samples 1 and 2 . As a result, the processes of thermomechanical fatigue developed in the samples, since both liquid and solid phases entered into contact with them. After complete crystallization under pressure, the pressed bronze was removed, and the surface of the samples was examined for the occurrence of thermomechanical fatigue cracks with a fixed cycling base.

The temperature of the crystallized billet of solid-liquid tin-zinc-lead bronze was $7800 \mathrm{C}$. The duration of the active pressing cycle was $3.0 \mathrm{~s}$., Pauses - $25 \mathrm{~s}$. The specific pressure during pressing was $\approx 1400 \mathrm{MPa}$.

Assessment of the number of cracks (n) was carried out on the test surface in the middle of the sample in a $3 \mathrm{~mm}$ section. The penetration depth of thermomechanical fatigue cracks was measured on the side surface of the sample. To reduce the measurement error of cracks due to the skin effect, the samples on the side surface were ground to a depth of $0.3 \mathrm{~mm}$. Previously, using magnetic-field test on the surface of the samples, the indicator was determined, $\mathrm{N}$ is the number of loading cycles until the first cracks appear. Subsequently, the samples were studied after 250, 500, 750, 1000, and 2500 pressing cycles. The experimental data were approximated according to the procedure [12] using Microsoft Excel software.

\section{Results and Discussion}

The results of studies of the influence of surface hardening regimes on the performance of steel 4X4VMFS DI22 are shown in the Table 1. 


\begin{tabular}{|c|c|c|c|c|c|c|c|c|c|}
\hline \multirow{2}{*}{$\begin{array}{c}\text { ite } \\
\mathrm{m} \\
\text { No } \\
\text {. }\end{array}$} & \multicolumn{2}{|c|}{$\begin{array}{c}\text { Heat } \\
\text { treatment } \\
\text { conditions }\end{array}$} & \multirow[t]{2}{*}{$\begin{array}{c}\text { Hardness, } \\
\text { HRC }\end{array}$} & \multirow[t]{2}{*}{$\begin{array}{c}\text { Face-hardening } \\
\text { Option }\end{array}$} & \multirow{2}{*}{$\begin{array}{c}\text { Hardne } \\
\text { ss layer, } \\
\text { HRC, } \\
\text { HV }\end{array}$} & \multirow[t]{2}{*}{$\begin{array}{c}\text { Cycling } \\
\text { base, } \\
\mathrm{N}\end{array}$} & \multirow[t]{2}{*}{$\begin{array}{l}\text { Number of } \\
\text { cracks, } \\
n, \text { pcs }\end{array}$} & \multirow{2}{*}{$\begin{array}{c}\text { Crack } \\
\text { depth, } \\
\mathrm{H}_{\text {avg }}, \\
\mathrm{mm}\end{array}$} & \multirow[t]{2}{*}{$\begin{array}{c}\text { Layer } \\
\text { depth, } \\
\text { mm }\end{array}$} \\
\hline & $\begin{array}{c}\mathrm{T}_{\text {quenc }} \\
\text { hing, } \\
{ }^{0} \mathrm{C}\end{array}$ & $\begin{array}{c}\mathrm{T}_{\text {tempe }} \\
\text { ring, } \\
{ }^{0} \mathrm{C}\end{array}$ & & & & & & & \\
\hline 1 & 1050 & 600 & $44 \mathrm{HRC}$ & - & $44 \mathrm{HRC}$ & $\begin{array}{c}122 \\
250 \\
500 \\
750 \\
1000 \\
2500\end{array}$ & $\begin{array}{c}60-80 \\
1 \\
1 \\
1 \\
1 \\
1\end{array}$ & $\begin{array}{c}0,001- \\
0,02 \\
0,7 \\
1,8 \\
2,0 \\
2,5 \\
3,1\end{array}$ & - \\
\hline 2 & 1050 & 600 & $\begin{array}{c}50-53 \\
\mathrm{HRC}\end{array}$ & $\begin{array}{l}\text { Nitriding, } 530^{\circ} \mathrm{C}, \\
20 \mathrm{hr} \text {. Medium - } \\
\text { dissociated } \\
\text { ammonia. } \\
\text { Layer depth } \approx 0,16 \\
\quad-0,18 \mathrm{~mm}\end{array}$ & $\begin{array}{c}860- \\
880\end{array}$ & $\begin{array}{c}16 \\
250 \\
500 \\
750 \\
1000 \\
1500 \\
2000\end{array}$ & $\begin{array}{c}7 \\
8 \\
18 \\
18 \\
20 \\
22 \\
22\end{array}$ & $\begin{array}{l}0,07 \\
0,18 \\
0,21 \\
0,22 \\
0,23 \\
0,23 \\
0,24\end{array}$ & $\begin{array}{c}0,18- \\
0,21\end{array}$ \\
\hline 3 & 1060 & 600 & & $\begin{array}{c}\text { Boriding, } \\
30 \% \mathrm{~B}_{4} \mathrm{C}, 70 \% \\
\mathrm{Na}_{2} \mathrm{~B}_{4} \mathrm{O}_{7}, \\
940^{\circ} \mathrm{C}, 8 \mathrm{hr} . \\
\text { Layer depth } \approx 0,04 \\
-0,06 \mathrm{~mm}\end{array}$ & 1800 & $\begin{array}{c}5 \\
250 \\
500 \\
750 \\
1000 \\
2500\end{array}$ & $\begin{array}{l}12 \\
12 \\
13 \\
15 \\
17 \\
17\end{array}$ & $\begin{array}{c}0,01 \\
0,01 \\
0,04 \\
0,07 \\
0,08 \\
0,1\end{array}$ & 0,1 \\
\hline
\end{tabular}

Table 1: The Influence of Surface Hardening Modes on the Performance of Steel 4X4VMFS DI22

The influence of surface hardening regimes on the performance of steel 4X4VMFS DI22 the dependences of the crack depth (Havg) and the number of cracks (n) on the number of loading cycles are shown in Fig. 2. Approximation of the experimental data was carried out according to the procedure [12] using Microsoft Excel software.

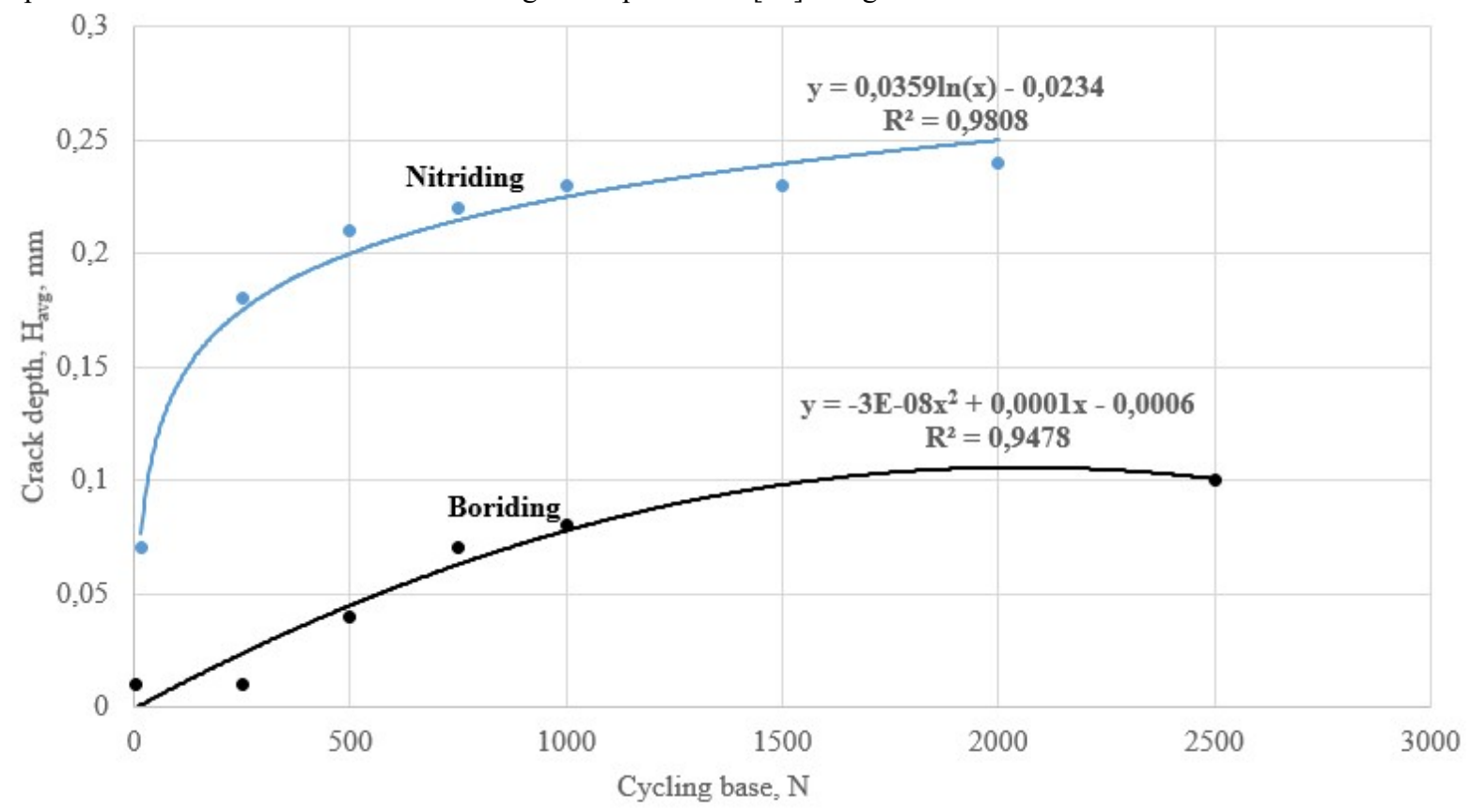

a) 


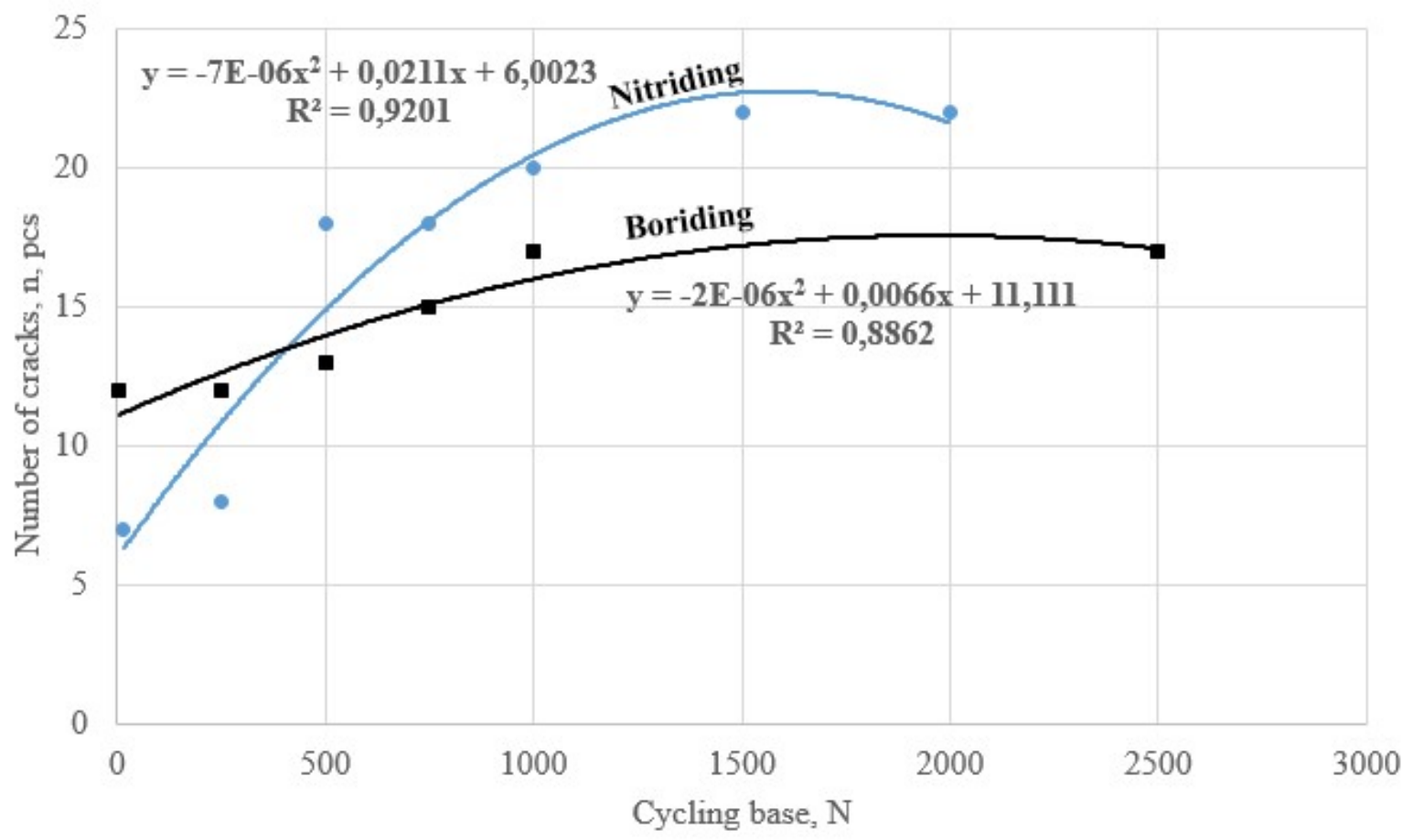

b)

Fig. 2: The Influence of Surface Hardening Regimes on the Performance of Steel 4X4VMFS DI22

[ a) the dependence of crack depth (Havg) on the number of cycles, b) the dependence of the number of cracks (n) on the number of cycles] An analysis of the data indicates that surface hardening with nitriding and boriding of 4X4VMFS DI22 negatively affects the resistance of the surface layers to the appearance of the first cracks, with boron samples having the lowest rate. In the case under consideration, a large number of cracks $(\mathrm{n}=12 \mathrm{pcs}$.) Appear clearly manifested after a short loading stage ( $\mathrm{N}$ $=5$ cycles). The crack propagation depth (Havg) initially does not exceed $0.01 \mathrm{~mm}$. With an increase in the number of loading cycles, the indicator of the depth of propagation of cracks, Hcp changes slightly; in this case, the crack depth at $\mathrm{N}=250$ cycles is commensurate with the depth of the borated layer $(\delta \approx 0.01 \mathrm{~mm})$. With a further increase, stabilization of crack development is noted both in a quantitative ratio and in depth. A similar pattern of the appearance and development of cracks is observed for the nitrided layer. However, the N index and crack depth (Havg) are significantly higher than for the boriding layer (Table 1, Fig. 2). The increased hardness and brittleness of the borated and nitrided layers and the presence of a high level of residual stresses contribute to the early occurrence of cracks. At the same time, the increased heat resistance and low thermal conductivity of the surface hardened layers, the presence of cracks, and relaxing stresses from external influences significantly inhibit the destruction of the material, which manifests itself in stabilization of crack formation during the subsequent accumulation of the number of cracks (n).

The process of destruction of steel samples 4X4VMFS DI22 without thermochemical treatment significantly differs from surface hardened (Fig. 3). 


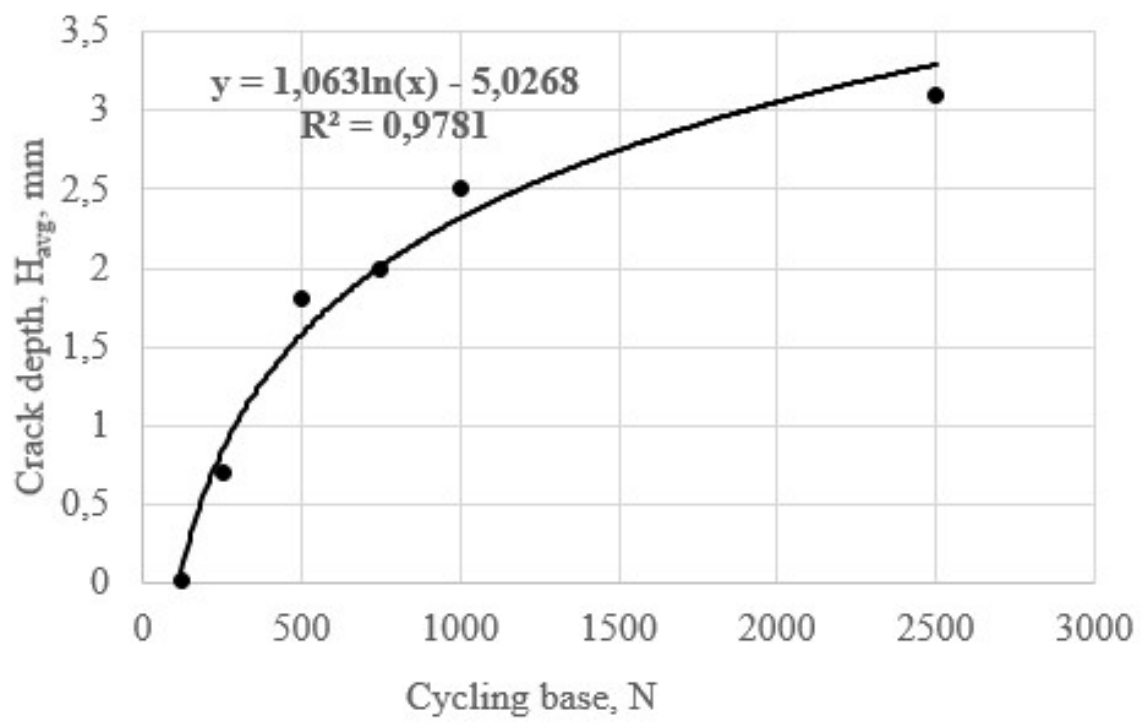

Fig. 3: Dependence of Crack Depth (Havg) on the Number of Cycles for Samples of Steel 4X4VMFS DI22 without Thermochemical Treatment.

The typical types of cracks in nitrided, borated and not subjected to thermochemical treatment samples are shown in Fig. 4.

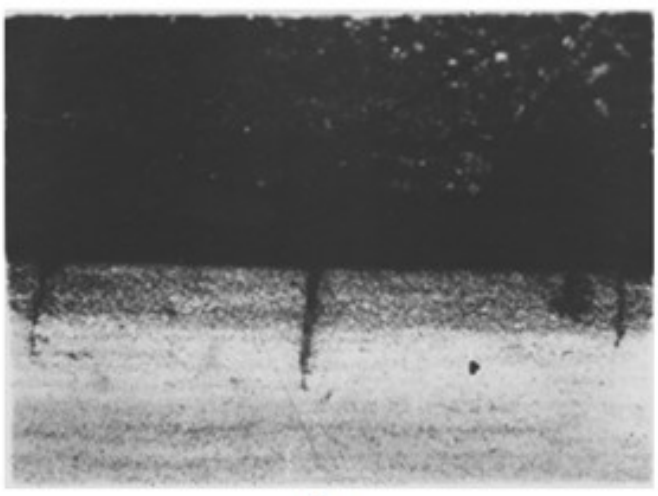

a)

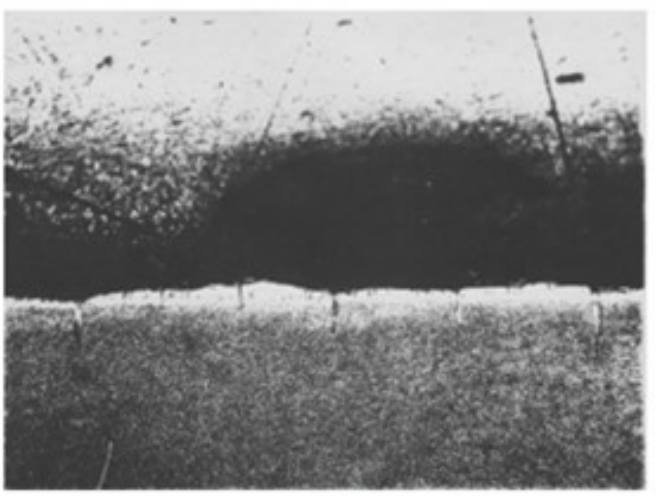

b)

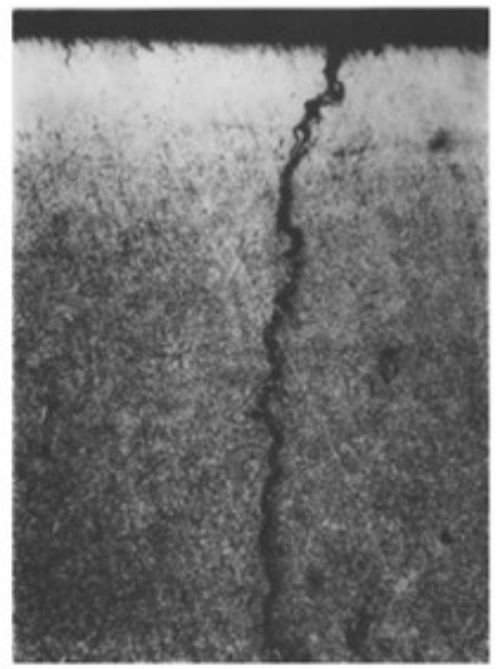

c)

Fig. 4: Typical Types of Thermomechanical Fatigue Cracks on Steel 4X4VMFS DI22

[ a) Nitrided Samples; b) Borated Samples; c) Without Thermochemical Treatment] 
The occurrence of the first thermomechanical fatigue cracks on samples not subjected to thermochemical treatment is observed at a later stage of cycling $(\mathrm{N}=122$ cycles). In this case, many tiny cracks (defects) with sizes $\approx 0.001-0.02$ $\mathrm{mm}$ appear on the surface of the samples (Fig. 4c). A further increase in the number of cycles ( $>250$ cycles) leads to the predominant development of single cracks. The penetration depth of single cracks (Fig. 4, c) is significantly greater than in the samples after nitriding and boriding (Fig. 4, a, b). Starting with N>2000 cycles, dents appear on the contact surface of samples without surface hardening. The results of microhardness measurements in the considered section of the specimen indicate an intense softening of the surface layers of the dies.

\section{Summary}

The performance of the stamping tool in the variant with diffusion hardening is determined by the specific laws of softening and destruction of contact zones. Moreover, the occurrence of cracks in the initial stages of operation is not decisive.

The positive effect of boriding and nitriding on the performance of AutoForge dies is associated with increased structural stability of the diffusion saturation zones, which ensures the maintenance of a high level of mechanical characteristics of the tool's working surfaces - hardness, strength, and as a result of high wear resistance.

\section{Conclusions}

The analysis of the results of studies of the laws of crack formation in steel 4X4VMFS DI22, subjected to various hardening methods, indicates the promising use of nitriding and boriding to increase the life of dies.

\section{Acknowledgements}

The work is performed according to the Russian Government Program of Competitive Growth of Kazan Federal University

\section{References}

[1] Geller Yu. A. Tool steel. 5th ed. M .: Metallurgy, 1983.- 527 p.

[2] Poznyak L.A., Skrychenko Yu.M., Tishaev S.I. Stamped steels. M .: Metallurgy, 1980 .-- 244 p.

[3] Trachtenberg B.F. Durability of stamps and ways to increase it. - Kuibyshev: Kbsh. Prince Publishing House, 1964 .-- 280 p.

[4] Yakovleva D.M., Mukhametzyanova G.F., Kharisov L.R., The Research of Stresses in the Molds of Injection Molding Machines // Procedia Engineering. - 2016. - Vol. 150, Is .. - pp. 453-457.

[5] Kolesnikov M.S., Mironova Yu.S., Mukhametzyanova G.F., Novikova I.E., Novikov V.Yu. Analog Studies of Thermomechanical Fatigue and Abrasive Wear of Cast and Forged Steels for Autoforge Dies // Metal Science and Heat Treatment. - T. 56. - No. 3 - 4. pp. 147 - 151.

[6] Lakhtin Yu. M. Material science: a textbook for higher technical educational institutions / Yu. M. Lakhtin, V. P. Leontiev. M.: Engineering, 1990. - 528p.

[7] Terentyev V. F. Fatigue of metallic materials. - M.: Nauka, 2003 .-- 254 p.

[8] M. Walter, J. Wilzer, L. Mujica Roncery, S. Weber, W. Theisen. Carbide precipitation of martensitic tool steels during tempering. European Conference on Heat Treatment and 21st IFHTSE Congress, May, 12th-15th, 2014 | Munich, Germany, Edited by Hans-Werner Zoch, Reinhold Schneider, Thomas Lübben, C) Arbeitsgemeinschaft Wärmbehandlung und Werkstofftechnik e. V. (AWT) Paul-Feller-Str. 128199 Bremen Germany, 2014 .-- pp. 383 $-390$.

[9] B. Kaufmann, H. Autenrieth, J. Hoffmeister, V. Schulze. Investigation on Short Time Tempering by Induction Heating of the low alloyed AISI4140 steel. European Conference on Heat Treatment and 21st IFHTSE Congress, May, 12th-15th, 2014 | Munich, Germany, Edited by Hans-Werner Zoch, Reinhold Schneider, Thomas Lübben, (C) Arbeitsgemeinschaft Wärmbehandlung und Werkstofftechnik e. V. (AWT) Paul-Feller-Str. 128199 Bremen Germany, 2014 .-- pp. 373 - 382.

[10] Kolesnikov MS, Mukhametzyanova GF, Zubkov EV, Optimization of Heat Treatment Modes of Steel 4Kh5MFS for Metal Conduits of Hot-Chamber Pressure Casting Machines According to Results of Endurance Tests in Molten TsAM-4-1 // Metal Science and Heat Treatment . - 2016.-- Vol., Is .. - pp. 14.

[11] A.S. No. 879400 of the USSR. A method for studying thermomechanical fatigue of materials / M.S. Kolesnikov, B.L. Kuznetsov, B.C. Kondratenko, A.G. Shishkin (USSR). Claim 02/20/1980, No. 2893336, Publ. 11/07/81, Bull. No. 41.

[12] Zotkin V.E. Methodology for the selection of materials and strengthening technologies in mechanical engineering: a training manual / V.E. Zotkin. M.: Eid "FORUM": INFRA-M, 2008. - 320 p. 